\title{
The Wound Healing Properties of Betulin from Birch Bark from Bench to Bedside
}

Author

Armin Scheffler

Affiliation

Niefern-Öschelbronn, Germany,

Key words

wound healing, split-thickness skin graft, burn wounds, Betulaceae, Betula pendula, Betula pubescens, betulin

$\begin{array}{ll}\text { received } & \text { October } 30,2018 \\ \text { revised } & \text { January 28, } 2019 \\ \text { accepted } & \text { January 29, } 2019\end{array}$

Bibliography

DOI https://doi.org/10.1055/a-0850-0224

Published online March 11, 2019 | Planta Med 2019; 85: 524-

527 @ Georg Thieme Verlag KG Stuttgart · New York |

ISSN 0032-0943

Correspondence

Dr. Armin Scheffler

Bussardweg 15/1, 75223 Niefern-Öschelbronn, Germany

Phone: +4972333580 , Fax: +497233974138

armin-scheffler@web.de

\section{ABSTRACT}

With central European approval in January 2016 for a betulinoleogel (Episalvan), used to accelerate wound closure in partial thickness wounds, the herbal active ingredient triterpene dry extract (betulin), from birch bark, was introduced into therapy for the first time. Clinical evidence of accelerated wound healing was provided in a new study design by means of intraindividual comparison of split-thickness skin graft donor wounds and burn wounds. Clinical results of a phase II study evidencing accelerated wound healing in the rare disease epidermolysis bullosa are also available, and a pivotal multi-centre phase III study is currently being conducted. The mode of action affects all three phases of wound healing (inflammation, migration, and differentiation), and it has been possible, in some cases, to shed light on this down to the molecular level. After temporary stimulation of the inflammatory phase, the keratinocytes migrate more rapidly to the wound closure and, finally, epidermal differentiation is stimulated. With this project, we have shown that scientifically founded new developments in phytotherapy are possible in Europe. The active ingredient is new and its indication is for the first time clearly proven in studies. Betulin-oleogel is the first drug of its indication and is patented until 2030. In addition, it is the first phytotherapeutic agent in surgery, and thus opens up a new therapeutic area for phytotherapy. The birch bark contains about $22 \%$ betulin in its cork tissue, meaning that the active ingredient is sustainably available from Northern Europe's wood-processing industry on a scale of several 100,000 t/a.

\section{Introduction}

Betulin-0leogel (Episalvan) is a drug approved for the first time worldwide by the EMA for the European Economic Area in 2016 (EU/1/15/1069/001) containing the triterpene-rich, purified dry extract from the bark of Betula pendula and B. pubescens, or hybrids of both species, as active ingredient. In what follows, this new birch bark extract will be referred to as "betulin" or "TE" for short, after the predominant substance contained in it, constituting around $80 \%$.

The indication is the treatment of superficial skin wounds (epidermis and upper dermis) and II a-degree burn wounds to the skin in adults. So far, there has been no drug approved in Europe with proven efficacy in accelerating wound closure of such wounds. Betulin-oleogel opens up the area of application of wound healing for phytotherapy, e.g. in plastic surgery, and especially in burn medicine.

The intention in what follows is to outline the development of this new drug.

\section{The Starting Point: Two Inventions}

The cork layer ( $\triangleright$ Fig. 1 ) of white-barked, tree-forming birches contains about $20-22 \%$ betulin alongside about 3-5\% closely related pentacyclic triterpenes such as betulinic acid, lupeol, erythrodiol, caffeoyl-betulin and oleanolic acid. 


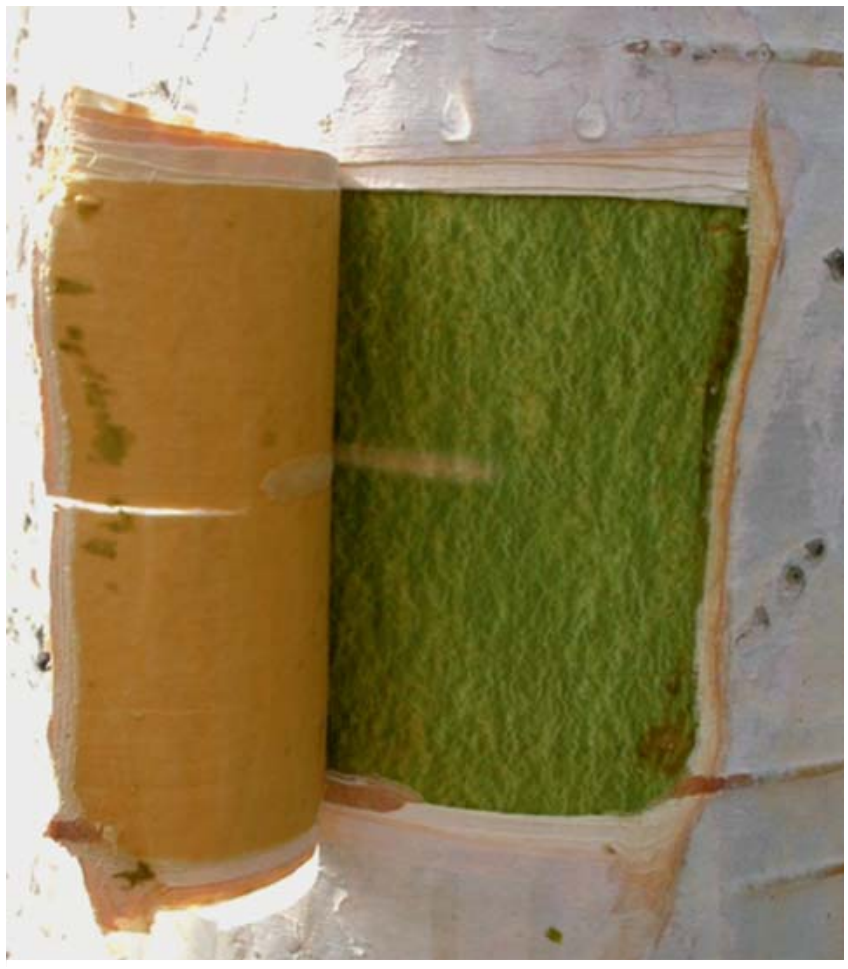

- Fig. 1 The cork layer can be removed relatively easily from the cork skin of the birch bark.

This concentration of a closely related group of active substances with the lead substance betulin in a relatively easily accessible plant tissue is extreme. Even more surprising, however, is the fact that betulin was first described in 1788 [1], but was only processed for the first time into an herbal active pharmaceutical ingredient with the innovation described here.

Two galenic properties of the refined, white, powdery dry extract that are important for its therapeutic application were unexpectedly revealed:

1. Betulin stabilises water-in-oil emulsions as a solid stabiliser and not as a surface-active substance. It thereby has a multifunctional effect, in that microparticles stabilise the interface between oil and water and at the same time form a gel network in the oil [2].

2. Betulin gelatinises oils. The result is thixotropic gels whose solidity is higher at body temperature than at room temperature. Thixotropic means they liquefy when agitated, so they can be applied comfortably and solidify when at rest [3].

Both inventions are patented $[4,5]$. The patents formed the basis for the foundation and financing of a pharmaceutical company (Birken GmbH in 2000, renamed as Birken AG in 2011, and Amryt AG since 2017).

First of all, the dry extract was subjected to toxicological and pharmacological safety testing with a view to drug development. Due to its excellent tolerability, we decided to develop the betulin emulsion into a base for a new surfactant-free cosmetic and to market this betulin-emulsion from 2004 (Imlan). Due to the con- tinuous need for production at increasing volumes, this approach led to a wealth of experience in the extraction of the active ingredient and in product manufacturing, which was essential for the development of the drug during the approval process. All quality assurance procedures, the acceptable range of process parameters (design space), the function and properties of the active substance and, last but not least, the pharmacological impact analysis were able to be developed during this time. Physical, chemical and pharmacological properties have been published by Laszczyk et al. [6].

\section{Drug Development}

The scientific interest in triterpenes such as betulin and its closest relatives has risen dramatically worldwide since 1995, when Pisha wrote an article in the first issue of Nature Medicine magazine about the discovery of betulinic acid counteracting malignant melanoma [7].

The effects described range from antiviral to tumour-inhibiting and anti-inflammatory, to anti-diabetic. Laszczyk summarises the tumour-inhibiting properties of relevant triterpenes [8]. Cytotoxic effects of cyclodextrin-bonded triterpenes from birch bark are described by Hertrampf et al. [9].

In addition to the drug to be applied, drug development requires an indication, which is to be tested. Through the application of the betulin-emulsion, we obtained evidence of efficacy in cases of actinic keratosis, which was also demonstrated in a small mono-centric phase II study [10]. However, the results of a multicentre phase II b study were too weak to brave an expensive approval process.

\section{Phase II}

The breakthrough came in 2010 with a phase II study on accelerating wound closure at split-thickness-skin graft donor sites. The new study design [11] made use of an intra-individual comparison of betulin-oleogel in combination with a non-adhesive, siliconised wound dressing versus the same wound dressing without any medication on a wound split into halves. A blind, independent evaluation was performed by 2 external experts on macro images of the wound. Every time the dressing was changed, re-epithelialisation was compared for both halves of the wound - unblinded, by the attending physicians (percentage estimate) and blinded, by the independent experts, on the basis of the photos, whereby the more strongly closed half was scored with a 1 , and the other with a 0 , and where no decision could be made, both halves were rated 0 . A score was established for each wound healing process. For details see Table 3 in [12].

To adjust the number of patients, an interim evaluation was planned after 20 evaluable processes. The result was surprisingly clear: out of 24 wounds, 20 were re-epithelialised faster with Episalvan, 2 with the wound dressing alone, and for 2, no decision could be reached. The result was highly significant $(p<0.0001)$ and the study was completed. A typical course of progress is shown in Fig. 3 in [12].

The results were published in more detail in Skin Pharmacology and Physiology [12], as were investigations into the validity of the study design, in the journal Trials [13]. 


\section{Consultation with the authorities for phase III}

The task was now to carefully prepare the substantiating studies of phase III. Is one even permitted to carry out a human study still with such a clear result? Scientific consultations at the Federal Institute for Drugs and Medical Devices and the European Medicines Agency resulted to important advices.

Therefore, three phase III trials were conducted in a total of 48 hospitals in 13 countries, from Valencia in Spain to Pori in Finland, from Birmingham in England to Varna in Romania and Athens in Greece, with 280 patients. In addition to 2 studies at the splitthickness-skin graft donor site, similar to in Phase II, 60 patients with 2 nd-degree burns were treated in the third study. A representative course of progress at a burn wound is shown in Fig. 1 in [14].

All three studies demonstrate faster wound closure with the use of betulin-oleogel, to a highly significant degree: by 1-2 days when determined by blind evaluation of photographs, and by $1.8-$ 2.5 days in open evaluation by the physician. What is impressive, and clearly relieves pain for the patient, is the rapid abatement of redness under betulin-oleogel. Even more important, however, is the long-term result. The wounds were re-examined after 3 months (Fig. 9 in [15]) and after one year.

In those patients where a difference could still be observed, as assessment was made as to whether the healed skin was more similar to healthy skin in texture, redness and pigmentation when treated with betulin-oleogel or with the wound dressing alone. The results are: texture $(27.5 \%$ vs. $7.1 \%$ after 3 months [p $<0.001$ ], $13.5 \%$ vs. $2.7 \%$ after 12 months [ $=0.002]$ ), redness ( $28.0 \%$ vs. $10.4 \%$ after 3 months [p $<0.001], 12.8 \%$ vs. $4.1 \%$ after 12 months $[p=0.015])$, and, in particular, pigmentation $(36.8 \%$ vs. $10.4 \%$ after 3 months [p<0.001], $23.6 \%$ vs. $8.9 \%$ after 12 months $[p=0.002])$. Where a difference in the scarring pattern could still be seen, the half treated with betulin-oleogel resembled the healthy skin significantly more frequently than did the re-epithelialised skin with the wound dressing alone. The results for the split-skin studies are published in detail in the journal Burns [14].

\section{Benefits for the patient and the approval process}

In general, accelerated wound healing has advantages for patients: reduced pain, lower risk of infection and fewer complications such as hypertrophic scarring. In general, the faster a wound closes, the better the cosmetic result. The new skin more closely resembles the uninjured skin. As already mentioned, this was impressively demonstrated in the phase III programme.

After careful evaluation of the study results and compilation of the approval dossiers on quality, harmlessness and clinical efficacy, the company applied to the EMA in October 2014 for central European approval as a drug with a new active ingredient. In November 2015, the Committee for Medicinal Products for Human Use issued a unanimously positive vote, and so, in January 2016, approval was granted for 28 European countries. In April 2016, the company was acquired by a stock-listed new founded company (now Amryt-Pharma), which is seeking further approval for Europe and the USA for the indication epidermolysis bullosa [16].

\section{Orphan Drug Designation for the Indication Epidermolysis Bullosa}

Both the EMA, in 2011, and the FDA, in 2014, issued an orphan drug designation for the active ingredient betulin for the indication epidermolysis bullosa. In this rare disease, which is also known as butterfly disease, the skin lacks certain anchor proteins due to hereditary factors, with the result that even slight mechanical stress results in detachment of the skin, with open wounds or blisters. Case reports and a phase II study on the acceleration of re-epithelialisation revealed birch bark extract to be beneficial for wound healing [17]. Verification by means of a substantiating phase III study was initiated in April 2017. An interim efficacy analysis at the end of 2018 recommended that the trial should continue with an increase of 48 patients to a total of 230. Results are expected in $\mathrm{H} 22019$ [16].

\section{Mode of Action: Acceleration in All 3 Phases of Wound Healing}

As already mentioned above, studies on the pharmacological effect of betulins were carried out during the development years, from 2006 to 2013. In collaboration with the research groups of Professor Schempp and Professor Merfort in Freiburg, as well as Professor Brandner in Hamburg, important evidence of the effect of betulins and the dry extract (TE) was obtained for the different phases of wound healing.

Wound healing takes place in three stages: the process begins with the inflammatory phase, in which mediators are released to attract macrophages, phagocytes and granulocytes into the wound in order to clean the wound. In the second phase, the inflammation is resolved, and the skin cells multiply and migrate in order to close the wound. The third and final phase is the longest lasting. The skin cells differentiate, mature and remodel the wound.

\section{Temporary stimulation of the inflammatory phase}

Inflammation mediators such as COX-2, IL-6 and IL-8 are temporarily up-regulated by TE thanks to its stabilisation of their mRNA (half-life increases by a factor of 3.5). Possible and investigated pathways for this process are p38 MAPK and HuR [18].

\section{Skin cells migrate faster}

TE influences the cell migration of primary human keratinocytes via the induction of IL- 6 and STAT3. Stabilisation of IL- 6 mRNA by TE leads to up-regulation of the transcription factor STAT3. In the scratch assay, it was possible to demonstrate faster closure of a split under the influence of TE (Fig. 9 in [18]).

Another effect on keratinocytes is the increased formation of lamellipodia, filopodia and stress fibres. Keratinocytes exhibit these phenomena when stimulated to migrate until they come into contact with neighbouring cells again (Fig. 10 in [18]). Clinically, this manifests in accelerated re-epithelialisation. 


\section{Accelerated maturation of the barrier}

For the final stage of wound healing, it was possible to show that TE stimulates keratinocyte differentiation markers to bring about maturation of the barrier. In the early differentiation phase, involucrin and keratin 10 are increasingly expressed, and in the late phase, transglutaminase. In the end, the terminal differentiation the apoptosis-like transition of keratinocytes to corneocytes - is specifically triggered by TE. Proof was able to be furnished ex vivo through apoptosis staining (Fig. 8 in [19]).

\section{Accelerated Wound Healing by Means of Episalvan is a Rational Phytotherapy}

With proof of the mode of action as outlined above, accelerated wound healing by means of betulin-oleogel (Episalvan) is a rational phytotherapy. It has been shown that chemically and physicochemically analysed plant extracts can be subjected to a precise biological impact analysis. However, it was helpful for this analysis that the therapeutic effect of faster re-epithelialisation had already been discovered in the phase II clinical observation test. As a result, the impact analysis was able to be much more effective and targeted.

\section{Acknowledgements}

The development of the described project was initiated by a grant of Forschungsfonds of Anthroposophical Society in Germany. Pharmacological studies especially regarding the mode of action were supported by Federal Ministry for Economic Affairs and Energy on the basis of a decision by the German Bundestag.

\section{Conflict of Interest}

Armin Scheffler is the inventor of patents regarding to the betulin emulsion and the betulin oleogel. He was director of Birken $\mathrm{GmbH}$ resp. Birken AG from its foundation in 2000 till April 2016. He is now retired.

\section{References}

[1] Lowitz JT. Über eine neue, fast benzoeartige Substanz der Birken. Chemische Annalen 1788; 2: 312-316

[2] Daniels R, Laszczyk MN. Betulin für tensidfreie Emulsionen. Pharm Ztg 2008; 153: 862-863

[3] Grysko M, Daniels R. Evaluation of the mechanism of gelation of an oleogel based on a triterpene extract from the outer bark of birch. Pharmazie 2013; 68: 572-577

[4] Scheffler A. Emulsion enthaltend einen Pflanzenextrakt, Verfahren zur Herstellung der Emulsion sowie zur Gewinnung des Pflanzenextraktes. Patent WO/2001/072315; 2001
[5] Scheffler A. Triterpenhaltiger Oleogelbildner, triterpenhaltiges Oleogel und Verfahren zur Herstellung eines triterpenhaltigen Oleogels. Patent WO/2005/123037; 2005

[6] Laszczyk M, Jäger S, Simon-Haarhaus B, Scheffler A, Schempp CM. Phys ical, chemical and pharmacological characterization of a new oleogelforming triterpene extract from the outer bark of birch (betulae cortex). Planta Med 2006; 72: 1389-1395

[7] Pisha E, Chai H, Lee IS, Chagwedera TE, Farnsworth NR, Cordell GA Beecher CW, Fong HH, Kinghorn AD, Brown DM et al. Discovery of betulinic acid as a selective inhibitor of human melanoma that functions by induction of apoptosis. Nat Med 1995; 1: 1046-1051. doi:10.1038/ $\mathrm{nm} 1095-1046$

[8] Laszczyk MN. Pentacyclic triterpenes of the lupane, oleanane and ursane group as tools in cancer therapy. Planta Med 2009; 75: 1549-1560

[9] Hertrampf A, Gründemann C, Jäger S, Laszczyk M, Giesemann T, Huber R. In vitro cytotoxicity of cyclodextrin-bonded birch bark extract. Planta Med 2012; 78: 881-889

[10] Huyke C, Reuter J, Rödig M, Kersten A, Laszczyk M, Scheffler A, Nashan D, Schempp C. Treatment of actinic keratoses with a novel betulin-based oleogel. A prospective, randomized, comparative pilot study. J Dtsch Dermatol Ges 2009; 7: 128-133

[11] Jäger S, Zahn T. Das neue Wund-Arzneimittel Episalvan ${ }^{\circledR}$ : Galenik und Studiendesign. Pharmakon 2016; 4: 349-355

[12] Metelmann HR, Brandner JM, Schumann H, Bross F, Fimmers R, Böttger $\mathrm{K}$, Scheffler A, Podmelle F. Accelerated reepithelialization by triterpenes: proof of concept in the healing of surgical skin lesions. Skin Pharmacol Physiol 2015; 28: 1-11

[13] Rennekampff HO, Fimmers R, Metelmann HR, Schumann H, Tenenhaus M. Reliability of photographic analysis of wound epithelialization assessed in human skin graft donor sites and epidermolysis bullosa wounds. Trials 2015; 16: 235

[14] Barret JP, Podmelle F, Lipový B, Rennekampff HO, Schumann H, Schwieger-Briel A, Zahn TR, Metelmann HR; BSH-12 and BSG-12 study groups. Accelerated re-epithelialization of partial-thickness skin wounds by a topical betulin gel: Results of a randomized phase III clinical trials program. Burns 2017; 43: 1284-1294. doi:10.1016/j.burns.2017. 03.005

[15] Scheffler A. Entwicklung des neuen Phytopharmakons Episalvan (Betulin) zur Wundheilung. Z Phytother 2017; 38: 100-106

[16] Amryt Pharma. Regulatory news. Available at www.amrytpharma.com/ investors/regulatory-news/. Accessed March 4, 2019

[17] Schwieger-Briel A, Kiritsi D, Schempp C, Has C, Schumann H. Betulinbased Oleogel to improve wound healing in dystrophic Epidermolysis Bullosa: a prospective controlled proof-of-concept study. Dermatol Res Pract 2017; 2017: 5068969

[18] Ebeling S, Naumann K, Pollok S, Wardecki T, Vidal-Y-Sy S, Nascimento JM, Boerries M, Schmidt G, Brandner JM, Merfort I. From a traditional medicinal plant to a rational drug: understanding the clinically proven wound healing efficacy of birch bark extract. PLoS One 2014; 9: e86147. doi:10.1371/journal.pone.0086147

[19] Woelfle U, Laszczyk MN, Kraus M, Leuner K, Kersten A, Simon-Haarhaus B, Scheffler A, Martin SF, Müller WE, Nashan D, Schempp CM. Triterpenes promote keratinocyte differentiation in vitro, ex vivo and in vivo: $\mathrm{A}$ role for the transient receptor potential canonical (subtype) 6. J Invest Dermatol 2010; 130: 113-123 